Supporting Information for

\title{
Dynamics of Ultrafast Intramolecular Charge Transfer with 1-tert-Butyl-6-Cyano-1,2,3,4-Tetrahydroquinoline (NTC6) in $n$-Hexane and Acetonitrile
}

by

\author{
Sergey I. DRUZHININ, *,a Sergey A. KOVALENKO, *,b \\ Tamara SENYUSHKINA, ${ }^{\mathrm{a}, \mathrm{b}}$ Klaas A. ZACHARIASSE*,a \\ ${ }^{a}$ Max-Planck-Institut für biophysikalische Chemie, Spektroskopie und Photochemische Kinetik, \\ 37070 Göttingen, Germany \\ ${ }^{\mathrm{b}}$ Institut für Chemie, Humboldt Universität zu Berlin, Brook-Taylor Strasse 2, \\ 12489 Berlin, Germany
}




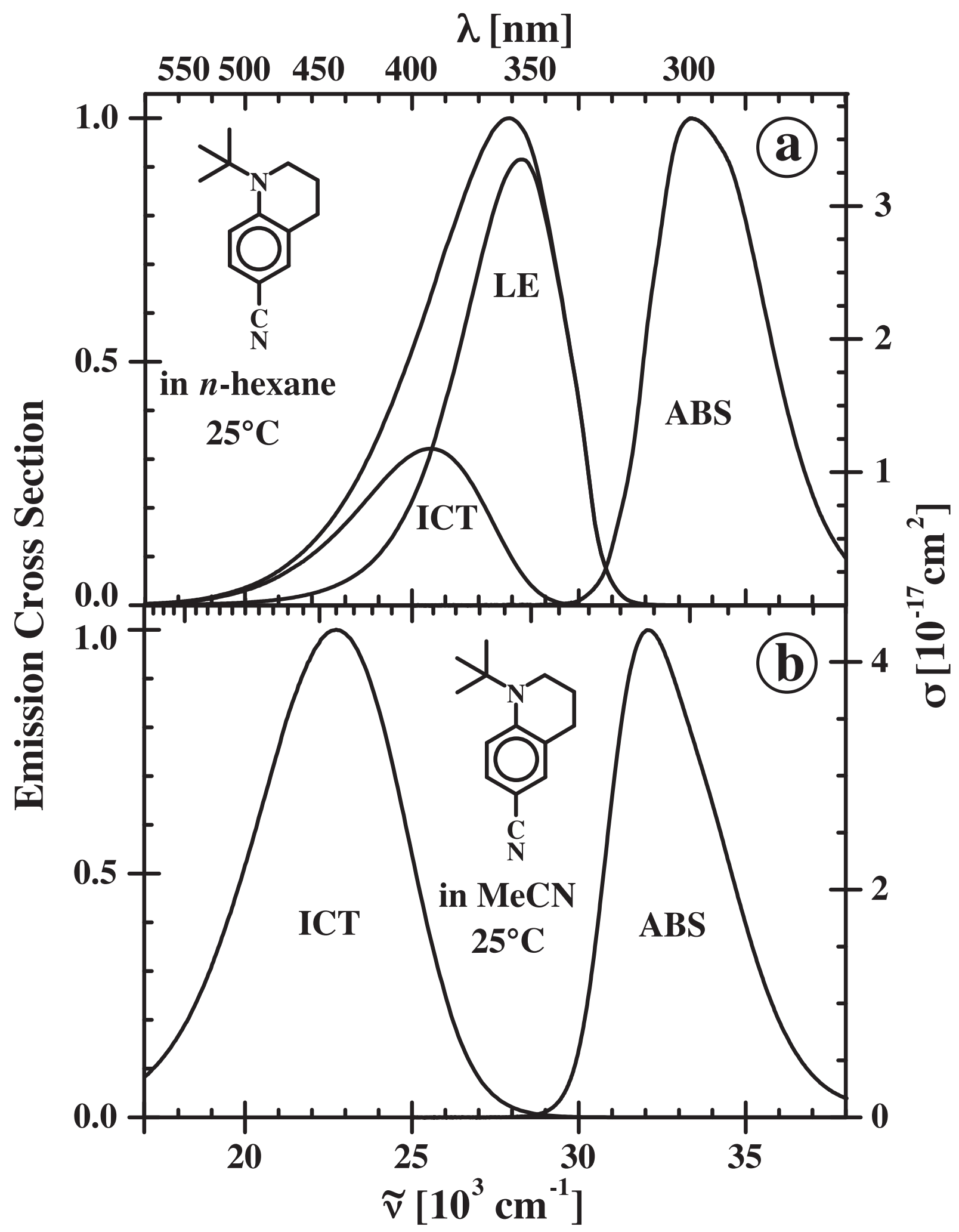

Figure S1. Absorption and fluorescence cross section spectra at $25^{\circ} \mathrm{C}$ of 1-tert-butyl-6-cyano1,2,3,4-tetrahydroquinoline (NTC6) in (a) $n$-hexane and (b) acetonitrile (MeCN). The overall fluorescence spectra are separated into the contributions of the LE and ICT emissions, see text. 